\title{
EFFICACY OF CHITOSAN AS A POST SPACE IRRIGANT ON BOND STRENGTH OF FIBER POSTS LUTED WITH SELF-ADHESIVE CEMENTS: AN IN-VITRO STUDY
}

\author{
Dalia Ali Ahmed Moukarab* and Shams Waaz Amgad Ali**
}

\begin{abstract}
Aim: To evaluate the efficacy of chitosan as a post- space irrigant on bond strength of glass fiber posts luted with self-adhesive resin cements.

Methodology: thirty single rooted human mandibular premolars with similar dimensions were decoronated to a standard root length of $15 \mathrm{~mm}$, endodontically treated and subjected to post preparation to a $10 \mathrm{~mm}$ length. Specimens were randomly divided in to 3 groups according to the post space irrigant (PSI) to be used in to group (Saline, EDTA, Chitosan) $n=10$ each. Following irrigation procedure glass fiber posts (GFP) (Glassix radiopaque, H Nordin, Chailly/Montyreux, Switzerlandand) were cemented using self-adhesive resin cement (RelyX U100). Specimens were sectioned perpendicular to the long axis into $1 \mathrm{~mm}$ thick slices. Three slices (one representative of each root third) from each specimen were subjected to push- out test and bond strength in MPa was statistically analyzed.
\end{abstract}

Results: the bond strength was significantly higher in both EDTA and Chitosan groups than saline group $\mathrm{P}<0.001$. Bond strength was significantly affected by the region of the root canal $\mathrm{P}<0.001$.

Conclusion: PSI affects the bond strength of GFP luted with self-adhesive resin cements. Chitosan can serve as a safer alternative for EDTA as a chelating agent. Chitosan as a PSI has a positive influence on the bond strength of GFP luted with self-adhesive resin cements.

KEYWORDS: Chitosan, Glass fiber post, Self-adhesive cement, Post space irrigant, Push out bond strength.

* Lecturer of Endodontics, Department of Endodontics, Faculty of Dentistry, Minia University

** Lecturer of Fixed Prosthodontics, Department of Fixed Prosthodontics, Faculty of Dentistry, Minia University 


\section{INTRODUCTION}

Success of endodontically treated teeth is not only determined by the debridement, and a fluid tight obturation of the root canal persi. It's more a multidisciplinary systematic process including accurate diagnosis, endodontic treatment and finally placement of a suitable coronal restoration ${ }^{(1)}$. Coronal leakage is considered as a silent killer, which tends to sneak up un-noticed for months causing extreme damage before its presence is acknowledged. (2)

For decades the focus of endodontic research has been on the apical seal of the root canal treatment. ${ }^{(3,4)}$ No doubt; it is well proven that the apical leakage lead to endodontic failure but the fact that a failure rate of $20-30 \%$ is found in teeth with well obturated teeth. Which has led to a significant increase in research focus on the coronal seal of endodontically treated teeth ${ }^{(5,6,7,8)}$.

In a retrospective study by Ray and trope (9) a clinical assessment of the incidence of apical pathosis after endodontic treatment. They found that the quality of coronal restoration is significantly more important than the quality of the obturation in regards to the periapical health Glass fiber posts are one of the many treatment modalities indicated for restoring endodontically treated teeth that need retention for a core build-up. ${ }^{(10,11)}$

Its modulus of elasticity is comparable to that of dentin which is a favorable characteristics allowing uniform, balanced stress distribution of the masticatory forces along the root canal walls ${ }^{(12,13)}$. At the same time the evolution of adhesive luting cements have also contributed to the high success rate of these types of posts ${ }^{(14,15)}$ and reduction in the risk of vertical root fracture 16 Furthermore; fiber posts are known to enhance esthetics and provide better light transmission to the apical region ensuring proper polymerization even in the deep areas of the root canal. ${ }^{(17)}$ However; the inherent draw back in post application is the need to prepare post space which eventually causes the deposition of a thick, heavy secondary smear layer on the root canal walls with remnants of gutta percha and sealer along with the dentin shatters ${ }^{(18,19,20)}$ Which of course jeopardizes the proper adhesion of the fiber post to dentin and may finally lead to leakage and secondary apical periodontitis ${ }^{(21,22)}$

Presence of this smear layer not only leads to leakage around the post but is considered a source of nutrition for microorganisms ${ }^{(23)}$

Pereira etal (24) studied the mode of failure of fiber posts via SEM and concluded that the main weak point in fiber post adhesion is the cement / dentin interface regardless of the type of luting cement or cementation protocol used. Most studies have shown comparable results where the prevalent mode of failure is between the cement and the dentin surface $^{(25)}$

Self-adhesive resin cements have been developed recently to simplify and overcome the sensitivity of the multiple step techniques. However; regarding the root canal system especially after postspace preparation the permeation ability through this thick smear layer and creation of a true hybrid layer is questionable ${ }^{(26)}$

From the previous context it is of paramount importance to plan the type of irrigant to be used after post space preparation not only to remove the smear layer but one which does not interfere with the setting reaction of the luting cement

So far ethylene diamine tetra-acetic acid EDTA is considered the most commonly used irrigant for smear layer removal ${ }^{(27,28)}$. However; in advertent erosion of periradicular dentin is observed when exposed to EDTA for more than 3 minutes ${ }^{(29,30,31)}$

Moreover; application of EDTA to dentin is known to alter the physical and chemical properties of dentin causing increased adherence of enterococcus faecalis which is microorganism strongly linked to post-treatment infections $(32,33,34)$ Together with its limited antibacterial activity and the raised environmental concerns ${ }^{(35)}$ 
From the above mentioned; many attempts have been made to find a suitable alternative to overcome these draw backs ${ }^{(36)}$. Chitosan, a recently introduced compound which is a natural polysaccharide produced from de acetylation of chitin ( obtained from shells of crabs and shrimp) ${ }^{(37)}$

Many medical fields have favored the use of such compound due to its abundant presence in nature and its more environmentally friendly characteristic 38 In addition to biocompatibility, biodegradability, and antibacterial activity which are few of its outstanding properties that have encouraged dental researchers to further integrate this compound into more fields of dentistry $(37,38,39)$

Silva etal ${ }^{(40)}$ found that chitosan produces smear layer removal comparable to that of EDTA with very little erosion than EDTA. In addition to Zhou etal 27 whom compared MTAD to chitosan in removing the smear layer . they found chitosan more efficient than MTAD especially in the apical third of the root canal . Even when using low concentrations of chitosan was capable of efficiently removing smear and providing a clean dentin surface ${ }^{(40,41)}$

It is worth mentioning that chitosan in contrast to EDTA; has a well -documented strong antibacterial activity against oral flora and is able to inhibit bacterial growth and suppress bacterial enzymes ${ }^{(\mathbf{4 2})}$ From the previous chitosan appears to be a justified candidate as an alternative for EDTA.

Few studies have investigated effect of irrigation solution after post space preparation on the bond strength of fiber posts. Most researches are directed to investigate the effect of chemical remnants of irrigation solutions during the chemo-mechanical preparation of the root canal which is actually diminished during the post space preparation; that removes a considerable amount of the dentin upon which they are attached to. ${ }^{(43)}$ The null hypotheses is that : 1- Chitosan as PSI does not influence bond strength of glass fiber posts luted with self-adhesive resin cements 2- Bond strength at different root regions exhibits similar bond strength values.

\section{AIM OF THE STUDY}

Evaluate the efficacy of chitosan as a post- space irrigant on bond strength of glass fiber posts luted with self-adhesive resin cements.

\section{MATERIALS AND METHODS}

\section{Specimen selection and preparation:}

Thirty intact human, single rooted mandibular premolars recently extracted for orthodontic reasons were used in this study. Only teeth with completely formed apices and no signs of external resorption or cracks were included, radiographs were taken in buccolingual and mesiodistal directions to confirm single root canal. The external surfaces of all samples were thoroughly cleaned of all soft and hard tissue debris after being immersed for 10 minutes in $5.25 \%$ sodium hypochlorite.

All teeth included in the present Study were with in comparable measurements and a statistical confirmation was done to eliminate any samples that were out of similar range of measurement. ${ }^{(44)} \mathrm{Se}$ lected samples were stored in $0.1 \%$ thymol solution to prevent them from becoming brittle or drying out. (45) Teeth were stored in distilled water with $0.1 \%$ thymol (Caelo, Hilden, Germany) for no longer than a month. One trained operator performed all root canal treatment, post space preparation and post cementation procedures for standardization purpose

All samples were decoronated to establish a standardized root length of $15 \mathrm{~mm}$ using a double coated diamond disc (Diatech, Coltene, Switzerland) mounted on a straight hand piece and under copious water coolant.

\section{Root canal treatment}

Working length was confirmed by passing a standard type K- file \# 10 (Dentsply, Maillefer: Ballaigues, Switzerland) in to the root canal till visible at the apex then retracted $1 \mathrm{~mm}$ coronally. Working length was set at $14 \mathrm{~mm}$. 
All specimens were instrumented using Protaper rotary files (Dentsply, Maillefer: Ballaigues, Switzerland) mounted on gear reduction, torque controlled endo motor (X-smart, Dentsply, Sirona, Switzerland). Canals were instrumented up to F4 and $1 \% \mathrm{NaOCl}$ (Egyptian company for household bleach-Egypt) was used in between files and finally flushed with $5 \mathrm{ml}$ of saline.

Root canals were dried using Protaper paperpoints (Dentsply, Maillefer: Ballaigues, Switzerland), then obturated in a single cone technique using the corresponding gutta percha point F4 (Dentsply, Maillefer: Ballaigues, Switzerland) and AH-Plus (Dentsply, Maillefer).

The excess gutta-percha was cut off using a red hot plugger $1 \mathrm{~mm}$ below the coronal end of specimens and sealed with flowable composite (Tetric EVO Flow, Ivoclar, Vivadent, Germany) and stored at $37 \mathrm{C}^{0}$ in $100 \%$ humidity for 7 days to ensure complete setting.

\section{Post space preparation}

Composite seal was removed with a round carbide bur ( BR-31, DIA-BURS, Mani, Japan ) from all specimens then Post space preparation was performed to a standardized length of $10 \mathrm{~mm}$ using the corresponding drill of the glass fiber post (GFP) system (Glassix radiopaque, H Nordin, Chailly/ Monteux, Switzerland) mounted on a low speed hand piece. ${ }^{(46)}$

An apical seal of $4 \mathrm{~mm}$ of the root canal filling was maintained undisturbed in each specimen. Periapical radiograph was taken to confirm complete removal of gutta percha in the coronal $10 \mathrm{~mm}$ and a $4 \mathrm{~mm}$ apical seal. Specimens were maintained moist by placing them in gauze sponge soaked in saline throughout the endodontic treatment and post- space preparation processes

The GFP were tried passively in the post space to ensure their fit down into the whole prepared depth.

\section{Grouping of the specimens and irrigation procedure:}

Each specimen was placed separately into an Eppendorf vial filled with silicon based impression material (Dentsply, Switzerland) up to $2 \mathrm{~mm}$ apical to the cervical margin which allowed simulation of the clinical simulation during polymerization so that only the cervical area of the root was exposed to the light emitted from the curing unit (preventing any light curing improvement via light diffusion through the root dentin) ${ }^{(43)}$

Specimens were then assigned randomly in to three equal groups 10 specimens each according to the PSI to be used in each group

Group (saline): $\mathrm{n}=10$ post space was irrigated with $5 \mathrm{ml}$ of saline for $3 \mathrm{~min}$

Group (EDTA): $\mathrm{n}=10$ post space was irrigated with $5 \mathrm{ml}$ of $17 \%$ EDTA for $3 \mathrm{~min}$

Group (chitosan): $\mathrm{n}=10$ post space was irrigated with $5 \mathrm{ml}$ of $0.2 \%$ chitosan for $3 \mathrm{~min}$.

Chitosan preparation: $0.2 \%$ chitosan was prepared by dilution of 0.2 gram chitosan (Nano Tech, dream land, Egypt) with a $90 \%$ deacetylation in $100 \mathrm{ml}$ of $1 \%$ acetic acid then stirred in a magnetic stirrer for 2 hours till a homogenous crystalline solution was obtained with a $\mathrm{PH}$ of 3.2. Each specimen was irrigated with $5 \mathrm{ml}$ of the assigned PSI for 3 min delivered with a plastic disposable syringe of 27 gauge needle placed to the full length of the post space, moved in an in and out movement. All post spaces were dried using a standard paper point \# 80(Dentsply, Maillefer).

\section{Post cementation procedure}

The GFP (Glassix radiopaque, H Nordin, Chailly/Montyreux, Switzerlandand) were cleaned with 70\% ethyl alcohol followed by application of a thin coat of silane coupling agent (Monobond Plus, Ivoclar Vivadent) ) using a microbrush and left for 1 min then dried with air jet. 
Self-adhesive resin cement (Rely XU100 3M, ESPE) was mixed according to manufacturer's instructions and delivered into the post space using a lentulo spiral (Dentsply, Maillefer) mounted on a low speed hand piece. Respectively the GFP were coated with cement and immediately seated in place and held under finger pressure for $2 \mathrm{~min}$.

Excess resin cement was removed using a microbrush then the posts were light cured for $40 \mathrm{sec}$ from the buccal then 40 more seconds from the lingual side with the curing unit tip 45 degree to the long axis of the post ( with $600 \mathrm{~mW} / \mathrm{cm}^{2}$ ). A $3 \mathrm{~mm}$ thick composite resin core (nano hybrid universal A3 shade 3M ESOE Z250XT, Seefeld, Germany) was placed to seal the coronal portion then Specimens were removed from the Eppendorf vial and then stored in $100 \%$ humidity at $37^{\circ} \mathrm{C}$ for 7 days. ${ }^{(24)}$

\section{Push-out bond strength test:}

All specimens were genteelly notched with a high speed carbide bur on the buccal surface then mounted into self-cured acrylic (cold cure acrylic resin, Acrostone, Egypt) in a standard cylindrical plastic ring in an upright position using a centralizing device.

Nine horizontal sections perpendicular to the long axis of the specimen from the cervical margin down were done to obtain a slice thickness if $1 \mathrm{~mm}$ each using a high- concentration double coated diamond disc (Diatech, Coltene, Switzerland) mounted on a straight hand piece and under copious water coolant.

The first 3 slices $(1,2,3)$ were termed coronal, the second 3 slices $(4,5,6)$ termed middle and finally the third 3 slices $(7,8,9)$ were termed apical. Once the slices of each specimen were obtained the diameter of post from the coronal and apical surfaces for slices $(2,5,8)$ - as representatives of each region- were recorded via a digital caliper. Push out test was performed for each selected slice.

Push out test was performed with a universal testing machine (Lloyd LRX, Lloyd Instruments,
Fareham Hants, UK) at $0.5 \mathrm{~mm} / \mathrm{min}$ attached to a $500 \mathrm{~N}$ load cell. Fig (1)

The slices were placed in an orientation such that the force was applied in an apico- coronal direction (till it provoked failure) by means of metal piston only contacting the post till dislodgment which was recorded in newtons $(\mathrm{N})$. Bond strength value was obtained in MPa via dividing the force (provoking failure) in $\mathrm{N}$ by the bonding area

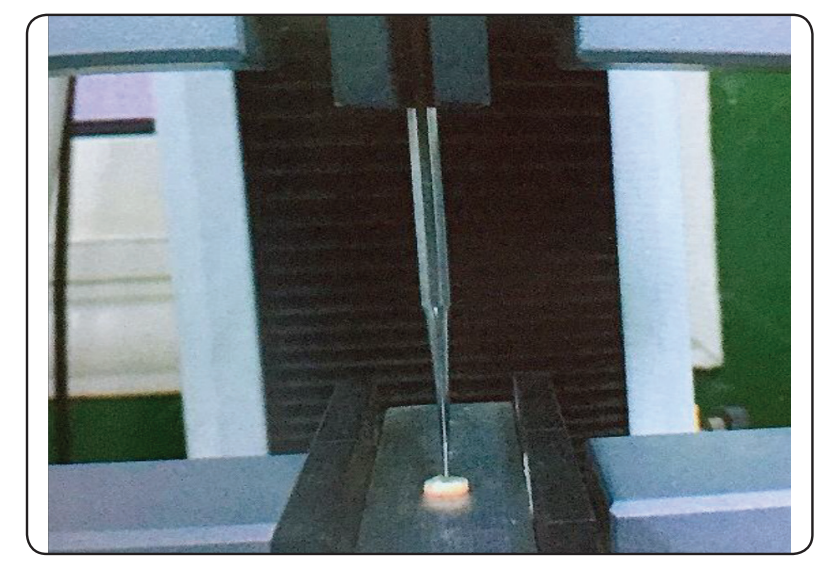

Fig. (1) Push out test (specimen under the piston of the universal testing machine)

Taking into consideration the conical shape of the post by using the following formula:

$$
\begin{aligned}
& \text { Area }=\pi(\mathrm{R}+\mathrm{r})\left[\left(\mathrm{h}^{2}\right)+(\mathrm{R}+\mathrm{r})^{2}\right] 0.5 \\
& \pi=3.4 \\
& \mathrm{R} \text { - Radius in the coronal surface in } \mathrm{mm} \\
& \mathrm{r} \text { - radius in the apical surface in } \mathrm{mm} \\
& \mathrm{h} \text { - Slice thickness in } \mathrm{mm}
\end{aligned}
$$

\section{RESULTS}

The descriptive analysis, in terms of means and standard deviation, of the push out bond strength values of fiber glass posts to intraradicular dentin subjected to the different tested (PSI) in different sites: Tab (1), Fig (2)

The descriptive analysis, in terms of means and standard deviation, of the push out bond strength values of fiber glass posts to intraradicular dentin in different sites: Tab 2, Fig 3 
TABLE (1): Push out bond strength between different irrigation types in different sites

\begin{tabular}{|c|c|c|c|c|}
\hline \multirow{2}{*}{ Site } & Saline & EDTA & Chitosan & \multirow{2}{*}{ P value } \\
\hline & $\mathrm{N}=10$ & $\mathrm{~N}=10$ & $\mathrm{~N}=10$ & \\
\hline \multirow{2}{*}{ Coronal third } & $(4.03-5.56)^{\mathrm{a}}$ & $(17.01-19.3)^{\mathbf{b}}$ & $(16.88-19.92)^{\mathbf{b}}$ & \multirow{2}{*}{$<0.001 *$} \\
\hline & $4.8 \pm 0.48$ & $18.14 \pm 0.85$ & $18.31 \pm 0.87$ & \\
\hline \multirow{2}{*}{ Middle third } & $(2.45-4.02)^{\mathrm{a}}$ & $(14.01-16.09)^{\mathbf{b}}$ & $(14.56-16.74)^{\mathrm{c}}$ & \multirow{2}{*}{$<0.001 *$} \\
\hline & $3.33 \pm 0.57$ & $15.13 \pm 0.7$ & $15.76 \pm 0.71$ & \\
\hline \multirow{2}{*}{ Apical third } & $(1.36-2.97)^{\mathrm{a}}$ & $(9.56-12.98)^{\mathbf{b}}$ & $(10.66-13.65)^{\mathbf{b}}$ & \multirow{2}{*}{$<0.001 *$} \\
\hline & $2.2 \pm 0.5$ & $11.54 \pm 0.98$ & $12.27 \pm 0.96$ & \\
\hline
\end{tabular}

One-Way ANOVA test for quantitative data between the three groups followed by post Hoc analysis between each two groups Superscripts with different small letters indicate significance difference between each two groups

*: Significant level at P value $<0.05$

TABLE (2): Push out bond strength between different sites in different irrigation types

\begin{tabular}{|c|c|c|c|c|}
\hline \multirow{2}{*}{ Irrigation type } & Coronal third & Middle third & Apical third & \multirow{2}{*}{ P Value } \\
\hline & $\mathrm{N}=10$ & $\mathrm{~N}=10$ & $\mathrm{~N}=10$ & \\
\hline \multirow{2}{*}{ Saline } & $(4.03-5.56)^{\mathrm{c}}$ & $(2.45-4.02)^{\mathbf{b}}$ & $(1.36-2.97)^{\mathrm{a}}$ & \multirow{2}{*}{$<0.001 *$} \\
\hline & $4.8 \pm 0.48$ & $3.33 \pm 0.57$ & $2.2 \pm 0.5$ & \\
\hline \multirow{2}{*}{ EDTA } & $(17.01-19.3)^{\mathbf{c}}$ & $(14.01-16.09)^{\mathbf{b}}$ & $(9.56-12.98)^{\mathrm{a}}$ & \multirow{2}{*}{$<0.001 *$} \\
\hline & $18.14 \pm 0.85$ & $15.13 \pm 0.7$ & $11.54 \pm 0.98$ & \\
\hline \multirow{2}{*}{ Chitosan } & $(16.88-19.92)^{\mathrm{c}}$ & $(14.56-16.74)^{b}$ & $(10.66-13.65)^{\mathrm{a}}$ & \multirow{2}{*}{$<0.001 *$} \\
\hline & $18.31 \pm 0.87$ & $15.76 \pm 0.71$ & $12.27 \pm 0.96$ & \\
\hline
\end{tabular}

One-Way ANOVA test for quantitative data between the three groups followed by post Hoc analysis between each two groups Superscripts with different small letters indicate significance difference between each two groups

*: Significant level at $P$ value $<0.05$

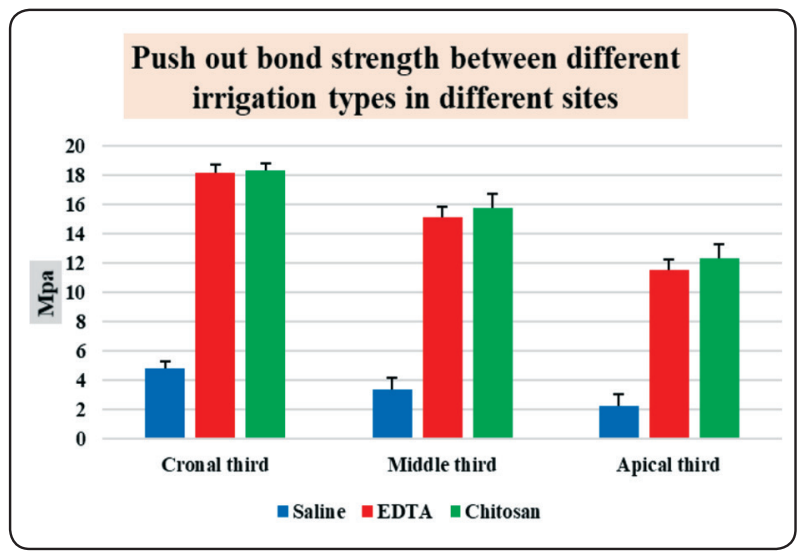

Fig. (2) Push- out bond strength between different irrigation types in different sites

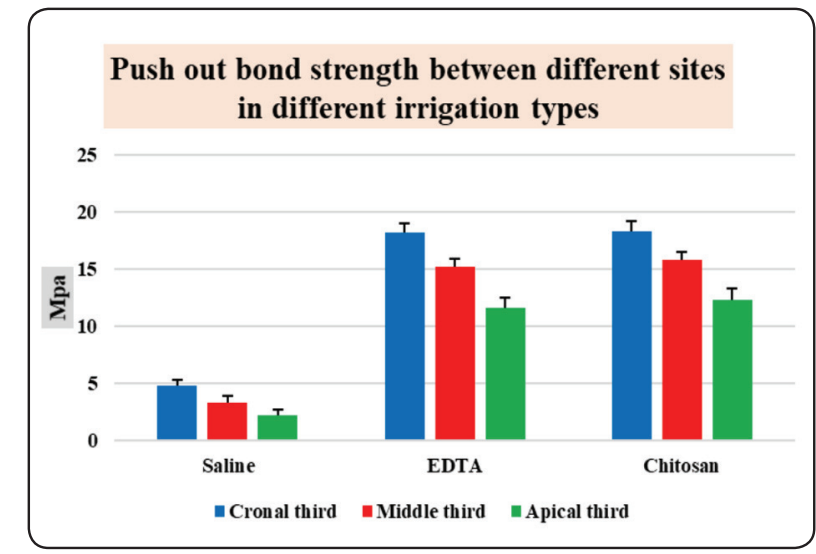

Fig. (3) Push out bond strength between different sites in different PSI types 
One-Way ANOVA test for quantitative data between the different irrigation types followed by post Hoc analysis between each two groups shown in Tab ( 3).

TABLE (3): Push out bond strength between different irrigation types regardless the site

\begin{tabular}{ccccc}
\hline & Saline & EDTA & Chitosan & Pvalue \\
\cline { 2 - 4 } & $\mathbf{N}=\mathbf{3 0}$ & $\mathbf{N = 3 0}$ & $\mathbf{N}=\mathbf{3 0}$ & \\
\hline Push out bond & $(1.36-5.56)^{\mathrm{a}}$ & $(9.56-19.3)^{\mathbf{b}}$ & $(10.66-19.92)^{\mathbf{b}}$ & $<0.001 *$ \\
strength & $3.44 \pm 1.19$ & $14.94 \pm 2.86$ & $15.44 \pm 2.65$ & \\
\hline
\end{tabular}

One-Way ANOVA test for quantitative data between the three groups followed by post Hoc analysis between each two groups

Superscripts with different small letters indicate significance difference between each two groups

*: Significant level at $P$ value $<0.05$

One-Way ANOVA test for quantitative data between the different root thirds followed by post Hoc analysis between each two groups Tab (4).

TABLE (4): Push out bond strength between different sites regardless the irrigation type

\begin{tabular}{ccccc}
\hline & Coronal third & Middle third & Apical third & Pvalue \\
\cline { 2 - 4 } & $\mathbf{N}=\mathbf{3 0}$ & $\mathbf{N}=\mathbf{3 0}$ & $\mathbf{N}=\mathbf{3 0}$ & $\mathbf{0 . 0 0 4 ^ { * }}$ \\
\hline Push out bond & $(4.03-19.92)^{\mathbf{b}}$ & $(2.45-16.74)$ & $(1.36-13.65)^{\mathrm{a}}$ & $8.67 \pm 4.73$ \\
strength & $13.75 \pm 6.48$ & $11.41 \pm 5.85$ & \\
\hline
\end{tabular}

One-Way ANOVA test for quantitative data between the three groups followed by post Hoc analysis between each two groups Superscripts with different small letters indicate significance difference between each two groups

*: Significant level at $P$ value $<0.05$

\section{DISCUSSION}

Relation between the quality of final coronal restoration and the overall prognosis of an ETT has been stressed on recently due high failure percentage in well obturated teeth with bad quality coronal restoration ${ }^{(1,5-9)}$

With the good success rate of glass fiber posts and the new advents in adhesive dentistry more practitioners are encouraged to use these systems , owing to their comparable modulus of elasticity to dentin a more favorable balanced distribution of force along the root canal walls ${ }^{(12,13)}$. Many studies have investigated the bond strength of GFP (47-51). Mostly comparing the different adhesive protocols used to our knowledge none have investigated the effect of chitosan on the bond strength of GFP.

Self-adhesive resin cements (Rely X U100) have good bond strength according to Bitter etal ${ }^{(52)}$ and Onay etal ${ }^{(53)}$. Chemically interacting with the hydroxyapatite of dentin ${ }^{(54)}$ they are moist- tolerant due to the phosphoric acid ester that requires wet dentin to develop this chemical reaction ${ }^{(55)}$ . Moreover it is a dual cured resin improves its polymerization even in deep areas of the root canal where the light transmission is decreased

Even though self-adhesive systems don't mainly depend on hybrid layer formation to establish a good bond strength, adaptation to the dentin wall 
increases the bond strength significantly as reported by Goracci etal ${ }^{(49)}$, Monticelli etal ${ }^{(56)}$.

This cement was chosen due to the rising popularity of these simply applied cements between practitioners that favor a one-step cementation system to the more complex and sensitive multistep systems. ${ }^{(43)}$ However; the heavy and thick smear layer forming over the post space prepared surface is likely to jeopardize the bond strength of selfadhesive resin cements. ${ }^{(18-20)}$ This justifies the investigation of effect of different PSI on the optimizing of the bond strength. EDTA has long been used as a chelating agent well documented for its ability to remove smear layer. ${ }^{(27,28)}$

While providing the desired aim of removing the smear layer it falls short of antibacterial property and stabilizing the dentin structure in addition to the environmental pollution issue and the unfavorable alteration in collagen which favors attachment of $\mathrm{E}$ faecalis - microorganism strongly linked to endodontic treatment failure- this has provoked the search for new biocompatible and environmentally friendly alternative chelating agent. ${ }^{(25,32-34)}$

Chitosan - a partially deacetylated chitin- which is known for its antibacterial, biocompatibility, biodegradability and bio adhesive properties seams as suitable alternative (41) Specially that it has been reported to provide comparable smear layer removal to that of $17 \%$ EDTA and $10 \%$ acetic acid with significantly less erosion of the peri-tubular dentin. ${ }^{(57)}$

Many researchers have encouraged the use of chitosan due to the fact that it has superior antibacterial properties and high inhibiting capabilities against recolonization of bacteria over the dentin surface. ${ }^{(58,59)}$

Moreover; it has been shown in previous studies that chitosan improves the mechanical and biological characteristics of dentin collagen which strongly relates to bond strength ${ }^{(34,58,60,61)}$
Regarding the present study human teeth were used this is because human teeth simulate- the bonding properties, modulus of elasticity, thermal conductivity and strength- of clinical situation. ${ }^{(62)}$

Teeth were decoronated to a standard root length of $15 \mathrm{~mm}$ this was to eliminate any coronal anatomy or access cavity variables and ensure no factorial variables were included into the study. $1 \%$ $\mathrm{NaOCl}$ was used in between file during endodontic treatment which is of low concentration that is reported not to interfere with resin polymerization and most probably the affected dentin surface is removed during post space preparation ${ }^{(63)}$. AH-plus root canal sealer selected to obturate the specimens which is an epoxy resin based sealer known to bond efficiently to dentin and to other composite resins and possesses no interference with polymerization of self-adhesive resin cements. ${ }^{(64,65)}$

Efficacy of irrigation solution is determined by time, concentration, volume. The PSI protocols for this study were set at 3 minutes and a volume of $5 \mathrm{ml}$ which is well documented for both EDTA and chitosan to provide efficient smear layer removal while decreasing risk of erosion. ${ }^{(66)}$

GFP were subjected to salinization process; step that has been documented to improve the chemical and mechanical retention of the GFP and resin cement. ${ }^{(49)}$

Bond strength was evaluated via push out test using a universal testing machine ; a method well documented to provide reliable results ${ }^{(67)}$ and applies more homogenous forces with less variability with in results and is more recommended for GFP. (68)

Regarding the push out bond strength of different PSI tested as expected the lowest bond strength was recorded with saline along the different root sites. Which comes in accordance with many previous studies. ${ }^{(27,31)}$ and was attributed to the thick heavy layer of smear formed during the post space preparation procedure and the in ability of saline to remove such a layer. 
On the other hand, both EDTA and chitosan recorded significantly higher bond strength in comparison with saline group in all three regions of the root. Regarding EDTA group high bond strength which was significantly higher than saline group $(\mathrm{p}<0.001)$ in agreement with previous studies. ${ }^{(69-71)}$

Due to the well documented fact that $17 \%$ EDTA is a powerful chelating agent capable of removing the smear layer and produces a clean dentin surface that is free for adaptation and the chemical reaction of the resin to dentin to form the ionic bonding which may explain the high bond strength. ${ }^{(54,72,73,74)}$

Chitosan; showed comparable results with EDTA recording high bond strength regardless of the site indicating the positive effect of application of $0.2 \%$ chitosan for $3 \mathrm{~min}$ to dentine surface on the bond strength of fiber posts cemented with self-adhesive resins this comes in accordance with previously recorded results. ${ }^{(40,41,57)}$

Chitosan $0.2 \%$ is reported to produce cleaner dentinal walls and efficiently more smear layer removal than did (15\% EDTA, 17\% EDTA and 10\% citric acid) with less erosion of the intraradicular dentin ${ }^{(57)}$. When self-adhesive cement comes into contact with clean dentin surface thought it's not likely to form dentin tags along the whole dentine wall but it's capable of chemically interacting with calcium ions of the hydroxyapatite via the carboxylic groups from the polyalkenoic acid producing an ionic bond which attributes to the bond strength. ${ }^{(54)}$

The absorbed part of chitosan or remnants that are attached to the intraradicular dentin actually has been reported to improve the mechanical and biological properties of collagen and improves the bond strength and durability. ${ }^{(59,60,75)}$

In addition to the antibacterial activity of chitosan that inhibits bacterial enzymes responsible for the degradation of dentin collagen. This leads to a more strong and stable dentin/ cement bond which also contribute to the bond strength. ${ }^{(58,59)}$

Regarding the bond strength of different sites '; a significant difference was fond among the root thirds regardless of the type of PSI used. the apical third showed significantly lower bond strength for all PSI at $(2.2,11.54,12.27)$ for saline, EDTA and chitosan respectively in comparison with the middle $(3.33,15.13,15.76)$ and coronal $(4.8$, $18.14,18.31) \mathrm{P}<0.001$. This was in agreement with results of previous studies ${ }^{(24,27)}$. Whom attributed the difference in bond strength to the larger diameters found in the coronal and middle thirds which provide more irrigant solution volume and contact resulting in effective smear layer removal while less volume reaches the apical third. Moreover; the smear layer which is characterized as more compacted into the dentinal tubules and densely attached to the dentin wall in the apical third while on the other hand in the coronal and middle thirds it is loose. ${ }^{(24,27)}$

It is noteworthy that the structure of dentine itself differs apically due to the decrease in the number of the dentinal tubules and the presence of a more sclerotic dentin nature which also explains the decrease in bond strength apically than coronally. ${ }^{(27)}$ Though the bond strength in (EDTA and chitosan) groups decreased within their own groups they still were significantly higher than the saline group which is probably due to the irritants' capability to remove the smear layer $(27,28,40)$

In contrast with the results of the present study many studies have found no statistically significant difference in bond strength among root regions ${ }^{(10,43}$, 76-78). This difference in the results may be due to the different methodologies used.

\section{CONCLUSION}

Within the limitations of the present study the following can be concluded:

1. PSI affects the bond strength of GFP luted with self-adhesive resin cements

2. Chitosan can serve as a safer alternative for EDTA as a chelating agent

3. Chitosan as a PSI has a positive influence on the bond strength of GFP luted with self-adhesive resin cements 
Further studies are required to evaluate the bond strength of GFP luted with self-adhesive cements after thermocycling and in vivo to establish the durability of such protocols.

\section{REFERENCES}

1. Mandke L. Impotance of coronal seal : preventing coronal leakage in endodontics. J Res Dent. 2016; 4: 71- 5.

2. Machtou P. Apial seal versus coronal seal. Endod Pract. 2006; 2: 19-26.

3. Amlani H, Hegde V. Microleakage : apical seal vs coronal seal. World J Dent. 2013; 4: 113-6.

4. Heling I, Gorfil C, Slutzky H, Kopolovic K, Zalkind M, Slutzky-Goldberg I. Endodontic failure caused by inadequate restorative procedures: Review and treatment recommendations.J Prosthet Dent. 2002; 87: 674- 84.

5. Madison S, Wilcox LR. An evaluation of coronal microleakage in endodontically treated teeth. Part III. In vivo study. JOE. 1988; 14: 455-8

6. Torabinejad M, Ung B, Kettering JD. In vitro bacterial penetration of coronally unsealed endodontically treated teeth. JOE. 1990; 16: 566-9.

7. - Saunders WP, Saunders EM. Assessment of leakage in the restored pulp chamber of endodontically treated multirooted teeth. Int Endod J. 1990; 23: 28-33.

8. Saunders WP, Saunders EM. Coronal leakage as a cause of failure in root-canal therapy: A review. Endod Dent Traumatol. 1994; 10: 105-8.

9. Ray HA, Trope M. Periapical status of endodontically treated teeth in relation to the technical quality of the root filling and the coronal restoration. Int Endod J. 1995; 28: $12-8$.

10. de Araújo DF, Chaves LP, Bim O J, Pimentel Garcia FC, Ishikiriama SK, Honório HM, Wang L.Influence of $2 \%$ chlorhexidine digluconate on bond strength of a glassfibre post luted with resin or glass-ionomer based cement. J Dent. 2014; 42(6):735-41.

11. Martelli Jr H, Pelllizzer EP, Rosa BT, Lopes MB, Gonini Jr A. Fracture resisitance of structurally compromised root filled bovine teeth restored with accessory glass fiber posts. Int Endod J. 2008; 41: 685-92.

12. Santana FR, Castro CG, Simamoto-Júnior PC. Influence of post system and remaining coronal tooth tissue on biomechanical behaviour of root filled molar teeth. Int Endod J. 2011; 44(5):386-394.
13. Barjau-Escribano A, Sancho-Bru JL, Forner-Navarro L, Rodríguez-Cervantes PJ, Pérez-Gónzález A, SánchezMarín FT. Influence of prefabricated post material on restored teeth: fracture strength and stress distribution. Oper Dent. 2006; 31(1):47-54.

14. Le Bell AM, Tanner J, Lassial LV, Kangasniemi I, Vallittu $\mathrm{P}$, Bonding of composite resin luting cement to fiber- reinforced composite root canal posts . Jour Oral Adhe Dent. 2004; 6: 319-25

15. Nova V, Karygianni L, Altenburger MJ ,Wolkewitz M, Kielbassa AM, WrbasKT. Pull-out bond strength of a fiber- reinforced composite post system luted with selfadhesive resin cements. Journal of Dentistry. 2013; 41: 1020- 6.

16. Plotino G, Grande NM, Bedini R, Pameijer CH, Somma F. Flexural properties of endodontic posts and human root dentin. Dental materials: official publication of the Academy of Dental Materials. 2007; 23 (9): 1129- 35.

17. Ebrahimi SF, Shadman N, Nasery EB, Sadeghian F. Effect of polymerization mode of two adhesive systems on pushout bond strength of fiber post to different regions of root canal dentin. Dental research journal. 2014; 11(1):32- 8.

18. Srirekha A, Rashmi K, Hegde J, Lekha S, Rupali K, Resh$\mathrm{mi}$ G. An in vitro evaluation of passive ultrasonic agitation of different irrigants on smear layer removal after post space preparation: a scanning electron microscopic study. J Indian Prosthodont Soc. 2013; 13(3): 240-6.

19. Serafino C, Gallina G, Cumbo E, Ferrari M. Surface debris of canal walls after post space preparation in endodontically treated teeth: a scanning electron microscopic study. Oral Surg Oral Med Oral Pathol Oral Radiol Endod. 2004; 97: 381-7.

20. Vichi A, Grandini S, Ferrari M. Comparison between two clinical procedures for bonding fiber posts into a root canal: a microscopic investigation. JOE. 2002; 28: 355-60.

21. Hayashi M, Takahashi Y, Hirai M, Iwami Y, Imazato S, Ebisu S. Effect of endodontic irrigation on bonding of resin cement to radicular dentin. European journal of oral sciences. 2005; 113(1) :70- 6 .

22. Perdigao J, Gomes G, Lee IK. The effect of silane on the bond strengths of fiber posts. Dental materials . 2006; 22(8):752- 8

23. Zand V, bidar M, Ghaziani P. A comparative SEM investigation of the smear layer following preparation of root canals using nickel titanium rotary and hand instruments. J Oral Sci. 2007; 49: 47-52. 
24. Pereira JR, Valle AL, Ghizoni JS, So MVR, Ramos MB, Lorenzoni FC. Evaluation of push-out bond strength of four luting agents and SEM observation of the dentine/fibreglass bond interface. Int Endod J. 2013; 46(10): 982-92.

25. Vieira EM, Basting RT, França FMG, Botelho do Amaral FL, Turssi CP. Bond Strength of Fiber Posts to Intraradicular Dentin after the Use of Ultrasonically Actived Irrigants. OHDM. 2018; 17 (1): 101-8.

26. Wu H, Hayashi M, Okamura K, Koytchev EV, Imazato S, Tanaka S, et al. Effects of light penetration and smear layer removal on adhesion of post-cores to root canal dentin by self-etching adhesives. Dental materials: official publication of the Academy of Dental Materials. 2009; 25(12): 1484- 92 .

27. Zhou H, Li Q, Wei L, Huang S, Zhao S. A comparative scanning electron microscopy evaluation of smear layer removal with chitosan and MTAD. Niger J Clin Pract 2018; 21: 76-80.

28. Crumpton BJ, Goodell GG, McClanahan SB. Effects on smear layer and debris removal with varying volumes of 17\% REDTA after rotary instrumentation. JOE. 2005; 31: 536-8.

29. Qian W, Shen Y, Haapasalo M. Quantitative analysis of the effect of irrigant solution sequences on dentin erosion. JOE. 2011; 37: 1437-1441.

30. Niu W, Yoshioka T, Kobayashi C. A scanning electron microscopic study of dentinal erosion by final irrigation with EDTA and $\mathrm{NaOCl}$ solutions. Int Endod J. 2002; 35: 934-939.

31. Bayram HM, Bayram E, Kanber M, Celikten B, Saklar F. Effect of different chelating solutions on the push-out bond strength of various root canal sealers. Biomed ResIndia. 2017; Special Issue: S401-S406.

32. Dornelles-Morgental R, Guerreiro-Tanomaru JM, de Faria- Junior NB, Hungaro-Duarte MA, Kuga MC. Antibacterial efficacy of endodontic irrigating solutions and their combinations in root canals contaminated with Enterococcus faecalis. Oral Surgery Oral Medicine Oral Pathology Oral Radiology Endodontics. 2011; 112: 396-400.

33. Moreira DM, Almeida JFA, Ferraz CCR, Gomes BPFA, Line SRP, et al. Structural analyses of bovine root dentin after use of different endodontics auxiliary chemical substances. JOE. 2009; 35: 1023- 27.

34. Kishen A, Sum CP, Mathew S, Lim CT. Influence of irrigation regimens on the adherence of Enterococcus faecalis to root canal dentin. JOE. 2008; 34: 850-854.
35. Spanó JC, Silva RG, Guedes DF, Sousa-Neto MD, Estrela C, Pécora JD. Atomic absorption spectrometry and scanning electron microscopy evaluation of concentration of calcium ions and smear layer removal with root canal chelators. JOE. 2009; 35: 727-30.

36. Ferrer-Luque CM, González-Castillo S, Ruiz-Linares M, Arias- Moliz MT, Rodríguez-Archilla A, Baca P, Antimicrobial residual effects of irrigation regimens with maleic acid in infected root canals. J Biol Res. 2015; 22: 1- 5.

37. Kurita K. Chemistry and application of chitin and chitosan. Polym Degrad Stabil 1998; 59: 117- 20.

38. Akncbay H, Senel S, Ay ZY. Application of chitosan gel in the treatment of chronic periodontitis. J Biomed Mater Res. 2007; 80: 290- 96.

39. Begüm Erpaçal B, Özkan Adigüzel O, Suzan CangülS, Musa Acartürk M . A General Overview of Chitosan and its Use in Dentistry. Int Biol Biomed J. 2019; 5(1): 1-11.

40. Silva PV, Guedes DF, Nakadi FV, Pécora JD, Cruz-Filho AM. Chitosan: a new solution for removal of smear layer after root canal instrumentation. Int Endod J. 2013; 46: 332-38.

41. Abraham S, Vaswani SD, Najan HB, Mehta DL, Kamble AB, Chaudhari SD. Scanning electron microscopic evaluation of smear layer removal at the apical third of root canals using diode laser, endoActivator, and ultrasonics with chitosan: An in vitro study. J Conserv Dent 2019; 22: 149-54.

42. Jaiswal N, Sinha DJ, Singh UP, Singh K, Jandial UA, Goel S. Evaluation of antibacterial efficacy of chitosan, chlorhexidine, propolis and sodium hypochlorite on Enterococcus faecalis biofilm: An in vitro study. J Clin Exp Dent .2017; 9: 1066-74.

43. Lima JF, Lima AF, Humel MM, Paulillo LA, Marchi GM, Ferraz CC. Influence of irrigation protocols on the bond strength of fiber posts cemented with a self-adhesive luting agent 24 hours after endodontic treatment. Gen Dent. 2015; 63(4): 22-6.

44. Yildiz C, Vanlıglu BA, Evren B, Uludamar A, KulakOzkan Y. Fracture Resistance of Manually and CAD/CAM Manufactured Ceramic Onlays. Journal of Prosthodontics. 2013; 22: 537- 42 .

45. Giannetopoulos S, Noort R, Tsitrou E: Evaluation of the marginal integrity of ceramic copings with different marginal angles using two different CAD/CAM systems. J Dent. 2010; 38: 980- 6 . 
46. Mao H, Chen Y, Yip KH, Smales RJ. Effect of three radicular dentin treatments and two luting cements on the regional bond strength of quartz fiber posts. Clin Oral Inv. 2011; 15: 869-78.

47. Erdemir A, Ari H, Gungunes H, Belli S. Effect of medications for root canal treatment on bonding to root canal dentin. J Endod. 2004; 30(2): 113- 16.

48. da Silva RS, de Almeida Antunes RP, Ferraz CC, Orsi IA. The effect of the use of $2 \%$ chlorhexidine gel in postspace preparation on carbon fiber post retention. Oral Surg Oral Med Oral Pathol Oral Radiol Endod. 2005; 99(3):372-377.

49. Goracci C, Sadek FT, Fabianelli A, Tay FR, Ferrari M. Evaluation of the adhesion of fiber posts to intraradicular dentin. Oper Dent. 2005; 30(5): 627-35.

50. Goracci C, Tavares AU, Fabianelli A. The adhesion between fiber posts and root canal walls: comparison between microtensile and push-out bond strength measurements. Eur J Oral Sci. 2004; 112(4): 353- 61.

51. Zicari F, Couthino E, De Munck J, et al. Bonding effectiveness and sealing ability of fiber-post bonding. Dent Mater. 2008; 24(7):967- 77.

52. Bitter K, Meyer-Lueckel H, Kanjuparambil JP, Neumann K, Kielbassa AM. Effect of luting agent and thermocycling on bond strengths to root canal dentine. Int Endod J. 2006; 39: 809-18.

53. Onay EO, Korkmaz Y, Kiremitci A. effect of adhesive system type and root region on the push-out bond strength of glass- fiber posts to radicular dentin. Int Endod J. 2010; 43: 259- 68 .

54. Geth HU, Dammaschke T, Zuchner H, Schafer E. Chemical analysis and bonding reaction of RelyX Unicem and bifix composite - a comparative study. Dent Mater. 2006; 22: 934-41.

55. Mazzitelli C, Monticelli F, Osorio R, Casucci A, Toledano M, Ferrari M. Effect of simulated pulpal pressure on selfadhesive cements bonding to dentine. Dent Mater. 2008; 24: 1156- 63.

56. Monticelli F, Osorio R, Mazzitelli C, Ferrari M, Toledano M. limited decalcification/ diffusion of self-adhesive cements into dentin. J Dent Res. 2008; 87: 974- 9.

57. Kamble AB, Abraham S, Kakde DD, Shashidhar C, Mehta DL. Scanning electron microscopic evaluation of efficacy of $17 \%$ ethylenediaminetetraacetic acid and chitosan for smear layer removal with ultrasonics: An In vitro study. Contemp Clin Dent 2017; 8: 621-6.
58. del Carpio- Perochena A, Clovis Monteiro Bramante CM, Duarte MAH , de Moura MR, Aouada FA, Kishen A. Chelating and antibacterial properties of chitosan nanoparticles on dentin. Restor Dent Endod. 2015; 40(3): 195-201.

59. Gajjela RS, Satish R K, Sajjan GS, Varma K M, Rambabu T, Vijaya Lakshmi B H. Comparative evaluation of chlorhexidine, grape seed extract, riboflavin/chitosan modification on microtensile bond strength of composite resin to dentin after polymerase chain reaction thermocycling: An in vitro study. J Conserv Dent. 2017; 20: 120-4.

60. Shrestha A, Friedman S, Kishen A. Photodynamically crosslinked and chitosan-incorporated dentin collagen. J Dent Res 2011; 90: 1346- 51.

61. Kishen A, Shi Z, Shrestha A, Neoh KG. An investigation on the antibacterial and antibiofilm efficacy of cationic nanoparticulates for root canal disinfection. J Endod 2008; 34: $1515-20$.

62. Alamin AM, Sakrana AA, Al-Zordk W A. Impact of Marginal Preparation Design on the Fracture Resistance of Endo-Crown All-Ceramic. JDMS. 2019; 18(4): 11-17.

63. Nikaido T, Takano Y, Sasafuchi Y, Burrow MF, Tagami J. Bond strengths to endodontically- treated teeth. Am J Dent. 1999; 12(4):177-80.

64. Kara TA, Tuncer S, Siso SH. Effect of Q Mix irrigant on the microhardness of root canal dentine. Aust Dent J 2015; 60: 163-8.,

65. Sousa NMD, Silva CFI, Marchesan MA. Ex vivo study of the adhesion of an epoxy-based sealer to human dentine submitted to irradiation with Er: YAG and Nd: YAG lasers. Int Endod J. 2005; 38: 866-70.

66. Silva PV, Costa- guedes DF, Pécora JD, da cruz-filho AM. Time-Dependent Effects of Chitosan on Dentin Structures Braz Dent J. 2012; 23(4): 357-61.

67. Yoshida Y, Van Meerbek B, Nakayama Y, Snauwaert J, Hellemans L, Lambrechts P. Evidence of chemical bonding at biomaterial hard tissue interfaces. Journal of Dental Research 2000; 79: 709-14.

68. Soares CJ, Santana FR, Castro CG . Finite element analysis and bond strength of a glass post to intraradicular dentin: comparison between microtensile and push-out tests. Dent Mater. 2008; 24(10):1405-11.

69. Dimitrouli M, Gunay H, Geurtsen W, Luhrs AK. Pushout strength of fibre posts depending on the type of root canal filling and resin cement. Clin Oral Investig. 2011; 15(2): 273-281. 
70. Gu XH, Mao CY, Liang C, Wang HM, Kern M. Does endodontic post space irrigation affect smear layer removal and bonding effectiveness? European journal of oral sciences. 2009; 117(5):597- 603

71. Soejima H, Takemoto S, Hattori M, Yoshinari M, Kawada $\mathrm{E}$, Oda Y. Effect of adhesive system on retention in posts comprising fiber post and core resin. Dental materials journal. 2013; 32(4): 659- 66 .

72. Haznedaroglu F. Efficacy of various concentrations of citric acid at different $\mathrm{pH}$ values for smear layer removal. Oral Surg Oral Med Oral Pathol Oral Radiol Endod. 2003; 96: 340-344.

73. Machado-Silveiro LF, González-López S, González-Rodríguez MP. Decalcification of root canal dentine by citric acid, EDTA and sodium citrate. Int Endod J. 2004;37:365-369

74. Shafiei F, Mohammadparast P, Jowkar Z. Adhesion performance of a universal adhesive in the root canal: Effect of etch-and rinse vs. self-etch mode. PLOS ONE. (2018); 13(4): 195- 9.
75. Everaets F, Torrianni M, VanLuyn M, Van Wachem P, Feijen J, Hendriks M,. Reduced calcification of bioprostheses , cross-linked via an improved carbodimide based method. Biomaterials. 2004; 25: 5523- 30.

76. Leme AA, Coutinho M, Insaurralde AF, Scaffa PM, da Silva LM. The influence of time and cement type on pushout bond strength of fiber posts to root dentin. Operative Dentistry. 2011; 36: 643-8.

77. Mirseifinejad R, Tabrizizade M, Davari A, Mehravar F. Efficacy of Different Root Canal Irrigants on Smear Layer Removal after Post Space Preparation: A Scanning Electron Microscopy Evaluation . Iranian Endodontic Journal. 2017; 12(2): 185-190

78. Kul E, Yeter KY, Aladag LI, Ayrancı LB. Effect of different post space irrigation procedures on the bond strength of a fiber post attached with a self-adhesive resin cement. J Prosthet Dent. 2016 ; 115(5): 601-5. 